\title{
Study of Neutron-DNA Interaction at the IPEN BNCT Research Facility
}

\author{
M. R. Gual ${ }^{1}$, O. Rodriguez ${ }^{1}$, F. Guzman ${ }^{1}$, A. Deppman ${ }^{2}$, J. D.T. Arruda Neto ${ }^{2}$, \\ V.P. Likhachev ${ }^{2}$, Paulo R. P. Coelho ${ }^{3}$, and P.T.D. Siqueira ${ }^{3}$ \\ ${ }^{1}$ Instituto Superior de Ciencias y Tecnologias Nucleares, \\ Ave. Salvador Allende Esq. Luaces, Quinta de Los Molinos, Plaza, C. Habana, AP 6163, Cuba \\ ${ }^{2}$ Instituto de Física, Universidade de São Paulo, \\ Rua do Matão, Trav. R, no. 187, CEP 05508-900, São Paulo, SP, Brazil \\ ${ }^{3}$ Instituto de Pesquisas Energéticas e Nucleares \\ Av. Prof. Lineu Prestes, 2242, CEP 05508-900, São Paulo, SP, Brazil
}

Received on 8 October, 2003

\begin{abstract}
Our group at the Laboratorio do Acelerador Linear (IFUSP- USP) is currently developing several studies related to the interaction of different kinds of radiation with DNA. Initially, our plan is to study the interactions proton-DNA, gamma-DNA and neutron-DNA. In this work we describe the most important features of the neutron-DNA study, which we plan to perform by selecting thermal, epithermal and fast neutrons. To improve the information about radiation-DNA interaction is important in order to achieve more secure and efficient cancer treatments by using radiation therapy. Nowadays, one important technique is the boron neutrons capture therapy, where neutrons are used to initiate a nuclear reaction at the tumor site. The effects of the neutrons on the health tissue, however, must be better understood. The study of neutron-DNA interaction, in this scenario, is of great importance. The research facility for Boron Neutron Capture Therapy (BNCT) in the IEA-R1 Reactor of the IPEN-CNEN/SP[1] will be used for studying the neutron-induced DNA damage. At present, we are evaluating the characteristics of the neutron flux at the biological sample, and we are carrying out simulations of the experimental procedure through Monte Carlos N Particle transport code system version 4C (MCNP-4C)[2] to find the experimental conditions necessary to minimize such contamination, and also verify the effects of those gamma's on the DNA molecule. The first step is the selection of filters configurations, which will allow us to irradiate the DNA sample with thermal, epithermal and fast neutrons. We present the results of our simulations, and describe the experimental setup show the best sets of materials necessary to obtain neutron spectra for different neutrons energies.
\end{abstract}

\section{Introduction}

The research facility for Boron Neutron Capture Therapy (BNCT) in the IEA-R1 Reactor of the IPEN-CNEN/SP[1] will be used for studying the neutron-induced DNA damage[3-5].

In order to reduce the gamma contamination and still have sufficiently high neutron fluxes for irradiation of DNA molecule, it will be necessary to place several neutron and gamma filters in the beam hole.

The experimental system was simulated with Monte Carlo MCNP-4C code[2] . The first step is the selection of filters material, which will allow us to irradiate the DNA sample with thermal, epithermal and fast neutrons and minimum gamma contamination. These included aluminum( $\mathrm{Al})$, bismuth(Bi), lead( $\mathrm{Pb})$, polyethylene(Poly), graphite $(\mathrm{G})$, lithium $(\mathrm{Li})$ and cadmium $(\mathrm{Cd})$.

Our purpose is to irradiate DNA molecule with thermal, epithermal and fast neutron in the BNCT Research facility at the IEA-R1 reactor. The results from simulation will be showed in this paper.

\section{Simulations}

To irradiate the DNA molecule we projected and constructed a support for the DNA samples. This is done controlling the position of a sample porter. The sample-carrier support consists of a section of a half-pipe or tube that is attached to two aluminum disks. The sample support is placed in this beam hole and fixed with screws at different locations as can be observed in Fig. 1.

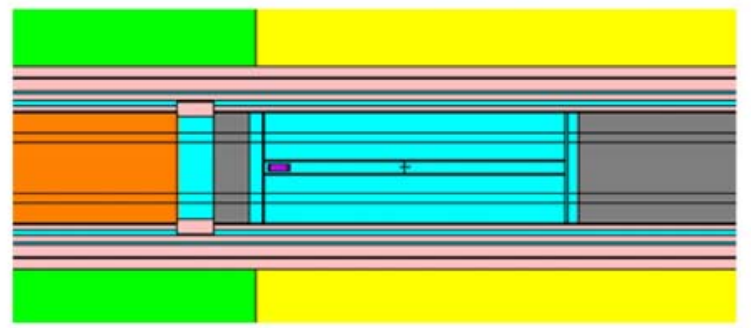

Figure 1. Superior view of the experimental facility simulated using MCNP-4C code with filter and support of sample located in the sample holder (without reflectors) 
The simulation is performed considering that the sample will be inside a holder, which will be placed on a support appropriately designed. All theses pieces are put inside a sample-carrier, consisting of a $1.3 \mathrm{~cm}$ radius half-tube, 30 $\mathrm{cm}$ long, with two disks at both ends, each disk having 6.3 $\mathrm{cm}$ diameter.

Fig. 2 shows the simulations with the used reflectors for obtain the optimal filters arrangement for epithermal irradiation to the DNA molecule.

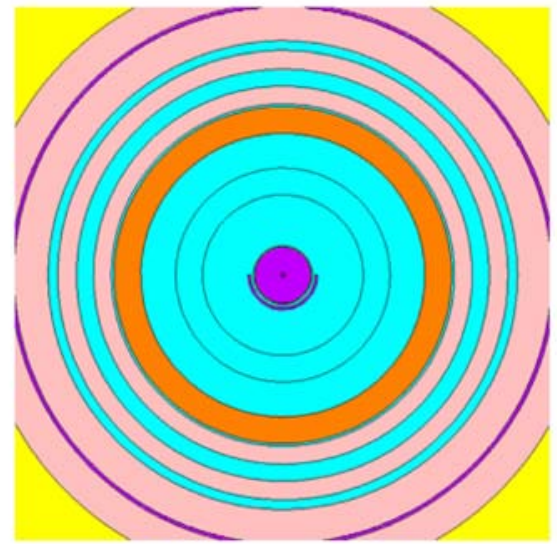

Figure 2. Frontal view of the beam holder with the sample porter and $\mathrm{Pb}(1 \mathrm{~cm})$-reflector.

The reactor source used in these calculations was the one reported in Ref. 1. The different tests were performed for optimal arrangement filters determinations.

\section{Results}

Several filters arrangements were investigated as detailed in the tables presented below.

The Cadmium was used to remove thermal neutrons from the neutron current but produces capture gammas.

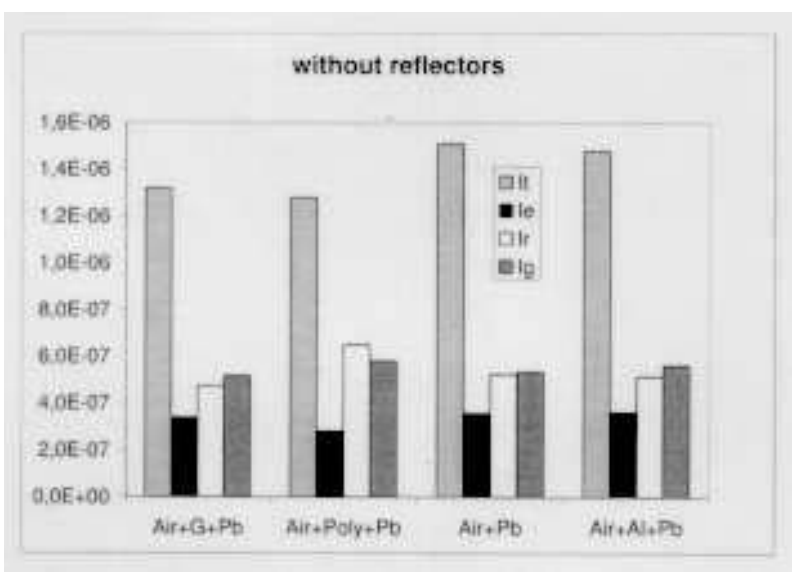

Figure 3. Relation of the thermal, epithermal, fast and gamma fluxes for some filter material located in the sample holder for thermal neutron irradiations.
The Lead filter allows lower the gamma contamination from neutron current and is used as reflector of neutrons however, not completely eliminate the gamma contamination.

The relation of the thermal, epithermal, fast and gamma fluxes (emissions/cm2) per source neutron for thermal neutron irradiations are shown in the Fig. 3 and a comparison of the thermal to epithermal, fast and gamma current ratio for theses arrangements are shown in the table I.

The highest thermal neutron current was obtained with the arrangement: C. It turned out that, after lead filter, neutrons are reflected. This configuration permits the highest relation It/Ig, where It is the thermal neutron current and Ig is the gamma current.

The optimal arrangement for epithermal neutron irradiation was obtained only with the inclusion of a reflector of $\mathrm{Pb}(1 \mathrm{~cm})$.

This reflector is located in the sample holder and consists of the one concentric tube.

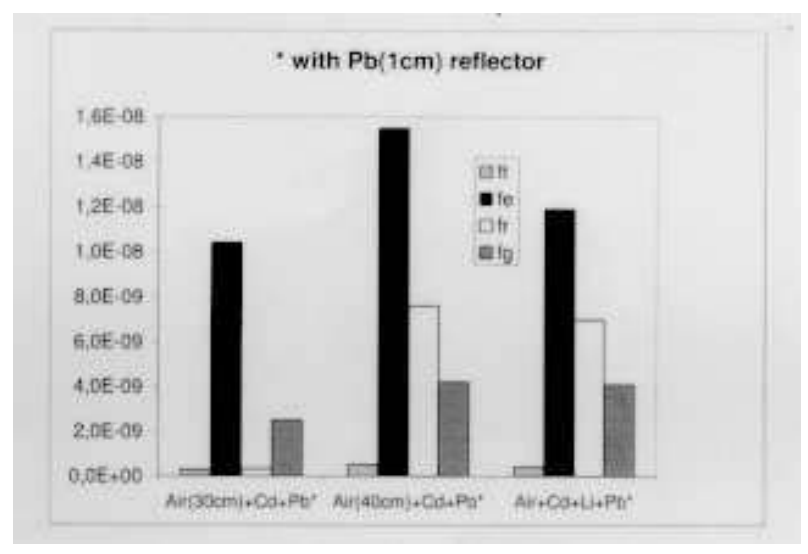

Figure 4. Relation of the thermal, epithermal, fast and gamma fluxes for some filter material located in the sample holder for epithermal neutron irradiations.

The contributions of the epithermal to thermal, the epithermal to fast and the epithermal to gamma fluxes ratio for irradiation with epithermal neutrons are presented below in the table II and the relation of fluxes is presented in Fig. 4.

The relation of the thermal, epithermal, fast and gamma current (emissions) per source neutron for fast neutron irradiations are shown in the Fig. 5

The optimal arrangement for epithermal neutron irradiation obtained is A. Such a configuration permits the highest $\mathrm{Fe} / \mathrm{Fg}$ relation.

Note that the Li material provided highest fast neutrons fluxes and is very effective in reducing gamma because it produces no capture gammas.

The optimal arrangement for fast neutron irradiation obtained is A. This configuration permits the highest Ir/It and Ir/Ie relation .

The fluxes and current calculations with Monte Carlo code MCNP-4C was performed with relative error lower than $5 \%$. 
TABLE 1. Comparison of the thermal to epithermal, fast and gamma current ratio for optimal arrangement with thermal neutrons.

\begin{tabular}{|c|c|c|c|c|c|}
\hline & Material & $\mathrm{I}_{n} / \mathrm{I}_{\gamma}$ & $\mathrm{I}_{t} / \mathrm{I}_{e}$ & $\mathrm{I}_{t} / \mathrm{I}_{r}$ & $\mathrm{I}_{t} / \mathrm{I}_{\gamma}$ \\
\hline $\mathrm{A}$ & {$[$ Air(30cm) $+\mathrm{G}(1 \mathrm{~cm})+\mathrm{Pb}(16.8 \mathrm{~cm})]+\mathrm{Pb}$} & 4.14 & 4.01 & 2.80 & 2.55 \\
$\mathrm{~B}$ & {$[$ Air(30cm)+Poly $(1 \mathrm{~cm})+\mathrm{Pb}(16.8 \mathrm{~cm})]+\mathrm{Pb}$} & 3.81 & 4.55 & 1.96 & 2.20 \\
$\mathrm{C}$ & {$[\operatorname{Air}(30 \mathrm{~cm}+\mathrm{Pb}(17.9 \mathrm{~cm})]+\mathrm{Pb}(4 \mathrm{~cm})$} & 4.48 & 4.24 & 2.88 & 2.83 \\
$\mathrm{D}$ & {$[$ Air(30cm) $+\mathrm{Al}(1 \mathrm{~cm})+\mathrm{Pb}(16.8 \mathrm{~cm})]+\mathrm{Pb}$} & 4.18 & 4.11 & 2.88 & 2.63 \\
\hline
\end{tabular}

TABLE 2. Comparison of the epithermal to thermal, the epithermal to fast and the epithermal to gamma fluxes ratio for irradiation with epithermal neutrons.

\begin{tabular}{|c|c|c|c|c|c|}
\hline & Material & $\phi_{n} / \phi_{\gamma}$ & $\phi_{e} / \phi_{t}$ & $\phi_{e} / \phi_{r}$ & $\phi_{e} / \phi_{\gamma}$ \\
\hline $\mathrm{A}$ & {$[$ Air $(30 \mathrm{~cm})+\mathrm{Cd}(1 \mathrm{~cm})+\mathrm{Pb}(16.8 \mathrm{~cm})]+\mathrm{Pb}^{*}$} & 5.60 & 28.7 & 3.26 & 4.16 \\
$\mathrm{~B}$ & {$[$ Air $(40 \mathrm{~cm})+\mathrm{Cd}(1 \mathrm{~cm})+\mathrm{Pb}(6.8 \mathrm{~cm})]+\mathrm{Pb}^{*}$} & 5.61 & 30.8 & 2.03 & 3.69 \\
$\mathrm{C}$ & {$[$ Air $(37 \mathrm{~cm})+\mathrm{Cd}(1 \mathrm{~cm})+\mathrm{Li}(6 \mathrm{~cm})+\mathrm{Pb}(3.7 \mathrm{~cm})]+\mathrm{Pb}^{*}$} & 4.75 & 29.0 & 1.70 & 2.90 \\
\hline
\end{tabular}

TABLE 3. Comparison of the epithermal to thermal, the epithermal to fast and the epithermal to gamma fluxes ratio for irradiation with fast neutrons.

\begin{tabular}{|c|c|c|c|c|c|}
\hline & Material & $\mathrm{I}_{n} / \mathrm{I}_{\gamma}$ & $\mathrm{I}_{r} / \mathrm{I}_{t}$ & $\mathrm{I}_{r} / \mathrm{I}_{e}$ & $\mathrm{I}_{r} / \mathrm{I}_{\gamma}$ \\
\hline $\mathrm{A}$ & {$[\operatorname{Air}(40 \mathrm{~cm})+\mathrm{Li}(6 \mathrm{~cm})+\mathrm{Pb}(1.8 \mathrm{~cm})]+\mathrm{Pb}$} & 3.09 & 1.60 & 3.32 & 1.60 \\
$\mathrm{~B}$ & {$[\operatorname{Air}(37 \mathrm{~cm})+\mathrm{Li}(6 \mathrm{~cm})+\mathrm{Pb}(16.9 \mathrm{~cm})]+\mathrm{Pb}$} & 3.71 & 1.16 & 3.04 & 1.70 \\
$\mathrm{C}$ & {$[\operatorname{Air}(37 \mathrm{~cm})+\mathrm{Cd}(1 \mathrm{~cm})+\mathrm{Li}(6 \mathrm{~cm})+\mathrm{Pb}(3.7 \mathrm{~cm})]+\mathrm{Pb}$} & 3.35 & 1.16 & 3.09 & 1.53 \\
\hline
\end{tabular}

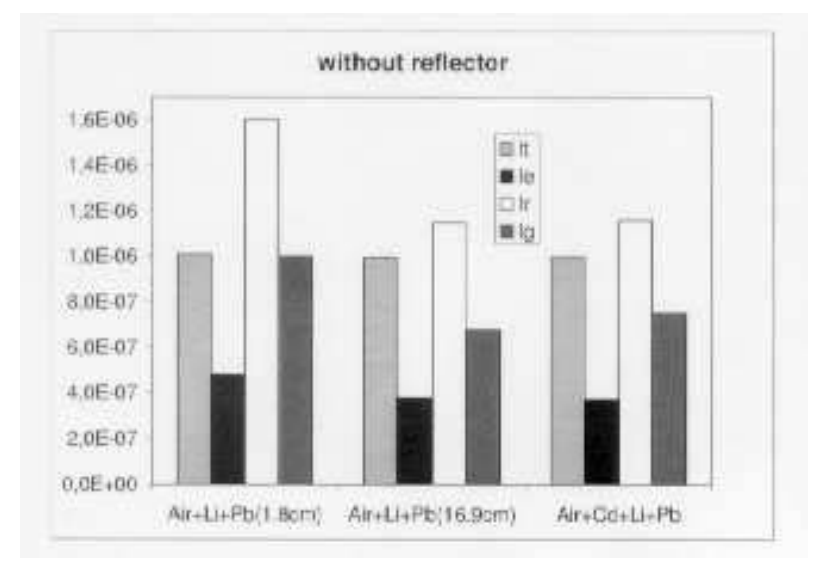

Figure 5. Relation of the thermal, epithermal, fast and gamma current for some filter material located in the sample holder for fast neutron irradiations.

\section{Conclusions}

In this work we presented results of MCNP simulations for different irradiations setups at the BNCT Research facility at the IAEA-R1 reactor.

We have shown that is possible to select filter in order to irradiate DNA samples with thermal, epithermal and fast neutron fluxes.

The experimental facility has been concluded; therefore the experimental part of this work will be performed in the near future.

\section{Aknowledgements}

The authors are thankful to the Latin-American Center of Physics for support this work.

\section{References}

[1] A.C. Coelho, Hernandes and P.T.D. Siqueira, Neutron Flux Calculation in a BNCT Research Facility Implemented in IAER1 Reactor, 10th International Symposium un Neutron Capture Therapy for Cancer, September 8-13, 2002, Essen, Germany.

[2] F. Briesmeister, MCNP - A general Monte Carlo N-particle transport code, version 4C, Los Alamos National Laboratory, LA-13709-M, (April, 2000).

[3] Dudley T. Goodhead, Int. J. Radiat. Biol. 56, 623 (1989).

[4] M. Stothein-Maurizot, M. Charlier, and R. Sabattier, Int. J. Radiat. Biol. 57, 301 (1990).

[5] A.A. STankus, et. al., Int. J. Radiat. Biol., 1995, 68, 1 (1995). 